\title{
MAPEAMENTO E ANÁLISE DE ARTIGOS CIENTÍFICOS SOBRE LINGUAGEM NA EDUCAÇÃO INFANTIL
}

\author{
Marielly Barbosa Silva Mota ${ }^{1}$; Lilian Miranda Bastos Pacheco ${ }^{2}$. \\ 1. Bolsista PIBIC/CNPq, Graduando em Licenciatura em Pedagogia, Universidade Estadual de Feira de Santana, e-mail: \\ mariellymota@hotmail.com.br \\ 2. Orientador, Departamento de Educação, Universidade Estadual de Feira de Santana, e-mail: lilianmbp01@ gmail.com
}

PALAVRAS-CHAVE: Educação Infantil; Estado da Arte; Linguagem.

\section{INTRODUÇÃO}

As pesquisas de metodologia Estado da Arte vêm tendo um aumento significativo e considerável no Brasil, principalmente nos últimos anos. São pesquisas que visam coletar, organizar, analisar, sistematizar e catalogar o conhecimento em uma determinada área de conhecimento, suporte textual, temática e período delimitado. Ferreira (2002) aponta que a pesquisa de cunho bibliográfico possui uma intencionalidade explícita em mapear e analisar a produção acadêmica em campos do conhecimento específico. Corroborando com esta perspectiva Soares (2000), infere que as pesquisas do tipo estado da arte ou estado do conhecimento não devem ter um ponto de chegada, e sim serem construídas continuadamente caracterizando os caminhos traçados por uma determinada área da ciência.

Nesta pesquisa buscou-se mapear e organizar os artigos científicos, sobre a temática linguagem na área de conhecimento da Educação Infantil, no período de 2004 a 2013, publicados em periódicos científicos, avaliados pelo QUALIS-CAPES de educação. O objetivo desta pesquisa é dar visibilidade ao saber produzido sobre a Educação Infantil, já que do ponto de vista legal, a Educação Infantil é considerada como a primeira etapa da Educação Básica e tem por finalidade o desenvolvimento integral da criança de 0 a 5 anos de idade mediante a seus aspectos físico, social, afetivo, intelectual e linguístico. Pretende-se compreender as ideias e demandas discutidas bem como as lacunas ou restrições existentes, e da mesma forma contribuir para os debates que estão em voga sobre a temática da linguagem na área da Educação Infantil, com o intuito de construir e sistematizar as discussões que tratem desta temática, já que desta pesquisa emergirá síntese e análise do saber já instituído.

\section{METODOLOGIA}

Esta pesquisa teve caráter bibliográfico específico, a metodologia Estado da Arte, que se distingue das demais por ser uma pesquisa com área de conhecimento, tema, suporte textual e período determinado. Pesquisas desse tipo podem apontar perspectivas para novas investigações e revelar como o tema tem sido abordado, em sua amplitude, intensidade, tendências teóricas e vertentes metodológicas.

Buscou-se localizar e analisar as produções científicas, em formato de artigo, realizadas acerca dos processos de aquisição e desenvolvimento da linguagem na Educação Infantil, entre os anos de 2004 a 2013. Esta pesquisa abrange dez anos de produção científica, em seis periódicos, classificados como internacionais com padrões de excelência na área de educação, segundo a avaliação de 2003, da QUALIS-CAPES. Ano que iniciou o projeto de pesquisa, ao qual este trabalho faz parte. 
A avaliação QUALIS é o conjunto de procedimentos empregados pela CAPES para classificar a qualidade da produção científica dos programas de pós-graduação, grupos de pesquisas e periódicos científicos. Essa classificação é realizada pelas áreas de avaliação seguindo critérios previamente definidos e aprovados pelo Conselho Técnico-Científico da Educação Superior (CTC-ES), são enquadrados em oito estratos que visam indicar a qualidade dos artigos e periódicos publicados e estão organizados em ordem decrescente de valor sendo A1 o mais elevado; A2; B1; B2; B3; B4; B5; C, com peso zero. (INFOCAPES, 2003)

Os periódicos classificados como internacionais, são: Cadernos de Pesquisa - FCC; Educação e Pesquisa-Revista da Faculdade de Educação da USP; Educação \& Realidade UFRGS; Educação e Sociedade - CEDES; Revista Brasileira de Educação - ANPEd; Investigações em Ensino de Ciências - UFRGS. Segundo a classificação da QUALIS-CAPES no ano de 2003 os cinco primeiros periódicos utilizados tiveram conceito A1, com exceção do periódico Investigações em Ensino de Ciências - UFRGS, que foi classificado com conceito B1, este foi incluído na pretensão de contemplar a área de Ciências para a Educação Infantil, vale destacar que na avalição do ano de 2015 o periódico obteve conceito A2.

Para a identificação dos artigos que abordassem a Educação Infantil foram utilizados sete descritores: creche, pré-escola, Educação Infantil, 0 a 5 anos, criança, infância e linguagem. A identificação consistiu na busca e localização dos descritores mencionados, nos títulos, resumos e palavras-chaves de cada artigo presente nos periódicos e períodos investigados.

\section{RESULTADOS E/OU DISCUSSÃO}

Para dar melhor visibilidade aos dados encontrados nesta pesquisa, segue a Tabela 1 , que categoriza os artigos segundo o periódico onde foi publicado e sua área de conhecimento, se são artigos relacionados à Educação Infantil ou artigos publicados abordando especificamente o campo da linguagem.

\begin{tabular}{|c|c|c|c|c|}
\hline \multicolumn{5}{|c|}{ TABELA- 01: Número de artigos sobre Educação Infantil por periódico } \\
\hline PERIÓDICOS & $\begin{array}{c}\text { ARTIGOS DA } \\
\text { ÁREA DA } \\
\text { EDUCAÇÃO } \\
\text { INFANTIL }\end{array}$ & $\%$ & $\begin{array}{c}\text { ARTIGOS SOBRE } \\
\text { LINGUAGEM }\end{array}$ & $\%$ \\
\hline Cadernos de Pesquisa - FCC & 40 & 34,78 & 1 & 20,0 \\
\hline $\begin{array}{c}\text { Educação e Pesquisa - Revista da } \\
\text { Faculdade de Educação da USP }\end{array}$ & 19 & 16,52 & 0 & 0 \\
\hline Educação \& Realidade - UFRGS & 13 & 11,30 & 0 & 0 \\
\hline Educação e Sociedade - CEDES & 24 & 20,86 & 3 & 20,0 \\
\hline $\begin{array}{c}\text { Revista Brasileira de Educação - } \\
\text { ANPEd }\end{array}$ & 17 & 14,78 & 1 & 0 \\
\hline $\begin{array}{c}\text { Investigações em Ensino de } \\
\text { Ciências - UFRGS }\end{array}$ & 2 & 1,73 & 0 & 100 \\
\hline TOTAL & 115 & 100 & 5 & 0 \\
\hline
\end{tabular}

Diante do número total de publicações sobre a área de conhecimento da Educação Infantil (115 ou 100\%) é possível perceber que o número de artigos que destacam ou versam sobre a linguagem (5 ou 4,34\%) é um número ínfimo. 
A quantidade de artigos apresentados na Tabela 1, que foram encontrados sobre Educação Infantil demonstra uma maior concentração de publicações (40 artigos ou 34,78\%) no periódico Cadernos de Pesquisa. Este tem publicações quadrimestrais, esta publicação é organizada pela Fundação Carlos Chagas. Seguido pelas publicações (24 artigos ou 20,86\%) do periódico, Educação e Sociedade, organizada pelo Centro de Estudos Educação e Sociedade (CEDES). Este configura-se como um dos mais importantes periódicos editados hoje na área da Educação no país. O periódico Educação e Pesquisa tem publicações trimestralmente e está vinculado a Faculdade de Educação da USP, o número de publicações encontradas nesta correspondeu a 19 artigos (ou 16,52\%). Já no periódico Revista Brasileira de Educação, que é publicada pela ANPEd - Associação Nacional de Pós-Graduação e Pesquisa em Educação, se dedica à publicação de artigos acadêmico-científicos, suas publicações são feitas trimestralmente, neste foram encontrados um número de 17 artigos ou $(14,78 \%)$ dos artigos na área da Educação Infantil.

O periódico Educação e Realidade é uma publicação da Universidade Federal do Rio Grande do Sul (Faculdade de Educação), apresenta artigos relacionados às várias áreas do campo da educação e suas interfaces. Foram localizados 13 artigos (ou 11,30\%). Já o periódico Investigações em Ensino de Ciências (IENCI), que está associado à Universidade Federal do Rio Grande do Sul, percorreu o caminho destoante dos demais periódicos, sendo encontrado o menor número de publicações (2 artigos ou 1,73\%) sobre a Educação Infantil, vale destacar que é um periódico de publicação quadrimestral, voltada exclusivamente para a pesquisa na área de ensino/aprendizagem de Ciências, o que mostra um distanciamento de suas questões para o ensino das crianças pequenas.

A partir da leitura inicial dos artigos científicos, foram identificados apenas 5 publicações, que apresentavam algum dos descritores propostos e que de fato versavam sobre a linguagem na Educação Infantil. Acerca da temática dos artigos encontrados, identificamos: A relação da linguagem na construção da identidade (Liliane Correia Toscano de Brito Dizeu e Sueli Aparecida Caporali, 2005; Zilda Maria Gesueli, 2006; Cínthia Najla Fahl Giammelaro, Zilda Maria Gesueli e Ivani Rodrigues Silva, 2013), aspectos do letramento em crianças pequenas (Cecília Goulart, 2006) e a linguagem oral como parte integrante da brincadeira (Dânia Monteiro Vieira Costa e Cláudia Maria Mendes Gontijo, 2011). A seguir o Quadro 1, apresenta as informações acerca da temática dos artigos. As categorizações dos artigos foram feitas a partir da identificação dos temas presentes, o que resultou em três grupos.

\begin{tabular}{|c|c|c|}
\hline \multicolumn{2}{|c|}{ Quadro 1: Categorização dos Artigos } & $\mathbf{N}^{\mathbf{0}}$ \\
\hline Temática & Artigos & 3 \\
\hline $\begin{array}{c}\text { Relação da linguagem na } \\
\text { construção da identidade }\end{array}$ & DIZEU et al. (2005); GESUELI (2006); GIAMMELARO et \\
al. (2013) & 1 \\
\hline $\begin{array}{c}\text { Aspectos do letramento na } \\
\text { Educação Infantil }\end{array}$ & GOULART (2006) & 1 \\
\hline $\begin{array}{c}\text { A linguagem oral como elemento } \\
\text { integrante da brincadeira }\end{array}$ & COSTA et al. (2011) & \\
\hline
\end{tabular}

Fonte: própria, dados do mapeamento.

Os autores e coautores possuem titulações variadas (graduandos, mestres, mestrandos, 
doutores e doutorandos), destes autores e coautores estão inseridos em programas de pósgraduação e/ou em grupos de pesquisas que contemplam diversas áreas de conhecimento: Educação, Educação Especial e Inclusiva, Linguagem, Linguística e Linguística Aplicada, e também a Fonoaudiologia. Destacamos como ponto positivo o fato da linguagem poder ser objeto de estudo de diferentes áreas, entende-se a linguagem como ferramenta interdisciplinar de ensino/aprendizagem habilidade cognitiva e comunicativa, que passa por um processo de aquisição e desenvolvimento.

\section{CONSIDERAÇÕES FINAIS}

De tudo o que discutimos acerca da produção acadêmica sobre linguagem na área da Educação Infantil no período de 10 anos, destacamos o uso da metodologia Estado da Arte, como instrumento basilar, desde o princípio ao fim da pesquisa. No que concerne à temática aqui estudada e apresentada, vale mencionar que, ainda que sejam encontrados estudos que destaquem a linguagem bem como sua influência e importância, além do efeito sobre distintas aprendizagens, percebe-se uma escassez referente ao estudo desta temática na área da Educação Infantil. Para tanto se equipararmos o número total de artigos sobre educação infantil localizados, que foram 115 publicações, esse número final (5 artigos) revela que, sobre os estudos que envolvam a linguagem, sobretudo no campo educacional, pouco tem se correlacionado à Educação Infantil.

No entanto tal condição não inviabiliza a sistematização e análise dos estudos que contemplem a temática da linguagem, ressaltando, que esta pode desenvolver-se gradativamente e de forma natural, em consonância com as experiências informais, pode ser adquirida antes mesmo do acesso destas crianças na instrução formal de ensino. Por estas considerações é possível admitir a linguagem como agente mediador para o processo de aquisição e desenvolvimento da oralidade, bem como a importância em adotar estratégias de ensino significativas e interventivas, uma vez que estas estratégias podem efetivamente contemplar a aquisição e desenvolvimento das competências linguísticas.

\section{REFERÊNCIAS}

COSTA. D. M. V.; GONTIJO. C. M. M. A linguagem oral como elemento integrante da brincadeira. Cadernos de Pesquisa, v.41 n.142 jan./abr. 2011.

DIZEU. L. C. F. de B; CAPORALI. S. A. A língua de sinais constituindo o surdo como sujeito. Educação e Sociedade, vol. 26, n. 91, p. 583-597, Maio/Ago. Campinas, 2005.

FERREIRA, N. As pesquisas denominadas "Estado da Arte". Educação e Sociedade. Ano XXIII, 79, 257-272, ago. 2002.

GESUELI, Z. M. Lingua(gem) e identidade: A surdez em questão. Educação e Sociedade, vol. 27, n. 94, p. 277-292, jan./abr. Campinas, 2006.

GIAMMELARO. C. N.F.; GESUELI, Z. M; SILVA. I. R. A relação sujeito/linguagem na construção da identidade surda. Educação e Sociedade, v. 34, n. 123, p. 509-527, abr.-jun. Campinas, 2013.

GOULART, C. Letramento e modos de ser letrado: discutindo a base teórico-metodológica de um estudo. Revista Brasileira de Educação v. 11 n. 33 set./dez. 2006.

INFOCAPES. Boletim informativo da CAPES, vol. 10, $\mathrm{n}^{\circ} 2$ - Brasília, CAPES, 2003.

SOARES, M. Alfabetização. Brasília: MEC INEP/COMPED, 2000. Série Estado do Conhecimento, ISSN 1518-3653, $\mathrm{n}^{\circ} 1$. 